\title{
Evaluation of Management Scenarios for Controlling Eutrophication in a Shallow Tropical Urban Lake
}

\author{
Zikun Xing ${ }^{1}$, Lloyd H. C. Chua², Jörg Imberger ${ }^{3}$ \\ ${ }^{1}$ School of Civil and Environmental Engineering, Nanyang Technological University \\ 50 Nanyang Avenue, Singapore, 639798 \\ zkxing@ntu.edu.sg \\ ${ }^{2}$ School of Engineering, Deakin University \\ Geelong Waurn Ponds Campus, 75 Pigdons Road, Waurn Ponds VIC 3216, Australia \\ lloyd.chua@deakin.edu.au \\ ${ }^{3}$ Centre for Water Research, University of Western Australia \\ M023, 35 Stirling Highway, Crawley 6009, Western Australia, Australia \\ jimberger@cwr.uwa.edu.au
}

\begin{abstract}
Urban lakes are typically smaller, shallower, and more exposed to human activities than natural lakes. Although the effects of harmful algal blooms (HABs) associated with eutrophication in urban lakes has become a growing concern for water resources management and environmental protection, studies focussing on this topic in relation to urban lakes are rare and knowledge of the ecological dynamics and effective management strategies for controlling eutrophication in urban lakes is lacking. This study applied an integrated three-dimensional hydrodynamics-ecological model for a small shallow tropical urban lake in Singapore and evaluated various management scenarios to control eutrophication in the lake. It is found that in-lake treatment techniques including artificial destratification, sediment manipulation and algaecide addition are either ineffective or possess environmental concerns; while watershed management strategies including hydraulic flushing and inflow nutrients reduction are more effective and have posed less environmental concerns. In this study, inflow phosphorus reduction was found to be the best strategy after evaluating the advantages and drawbacks of the management strategies studied. Runoff from the watershed exerts significant influence on urban lakes and thus an integrated water resources management at the watershed level is critical for the control of eutrophication.
\end{abstract}

Keywords: urban lakes, water quality modelling, ELCOM-CAEDYM, eutrophication, management scenarios.
(C) Copyright 2014 Authors - This is an Open Access article published under the Creative Commons Attribution License terms http://creativecommons.org/licenses/by/3.0). Unrestricted use, distribution, and reproduction in any medium are permitted, provided the original work is properly cited.

\section{Introduction}

Compared to natural lakes, urban lakes are characterized by having a smaller size, shallower depth, and larger ratio of watershed area to lake surface area [1]. A large proportion of the urban lakes are man-made with the purposes of storing rainwater, water supply or recreational uses [2]. Urban lakes tend to be more impacted by human activities from receiving larger and poorer quality inflows from urban watersheds. Thus, urban lakes receive higher nutrient loadings and have more severe water quality issues such as eutrophication and reduced health $[3,4]$, compared to natural lakes. With excessive addition of nutrients, especially phosphorus, the water body can become eutrophic or even hypereutrophic with undesired effects such as harmful algal blooms which would pose serious environmental and management problems [5]. In recent decades, urbanization has led to significant increases of nutrient enrichment levels in urban lakes and as a result, there have been more occurrences of algal bloom events $[6,7]$. While the water quality problems in urban lakes remains a challenge for watershed and lake 
management, there are comparatively fewer studies focusing on urban lakes and we have little knowledge of their ecological dynamics and management strategies to effectively control eutrophication $[1,3]$.

In this paper, we present a numerical modelling study for a small shallow urban lake located in a tropical region using an integrated hydrodynamicsecological model. After calibrating the model, several management scenarios including watershed management and in-lake treatment were tested with the model. The results obtained and the advantages and disadvantages of the management scenarios studied are evaluated and discussed.

\section{Methodology}

Kranji Reservoir $\left(1^{\circ} 25^{\prime} \mathrm{N}, 103^{\circ} 43^{\prime} \mathrm{E}\right)$ is a small and shallow, tropical urban reservoir located in Singapore (Figure 1A) formed by the impoundment of Kranji River in the 1970s. The reservoir experiences episodes of eutrophication and recurrent cyanobacteria blooms. The lake surface area is $3.0 \quad 10^{6} \mathrm{~m}^{2}$ and catchment area is $5.610^{7} \mathrm{~m}^{2}$. The average depth of Kranji Reservoir is 5 meters while the depth at the deepest location is about 20 meters. The reservoir receives base flow and storm runoff from its main tributaries and the direct precipitation on the reservoir surface.
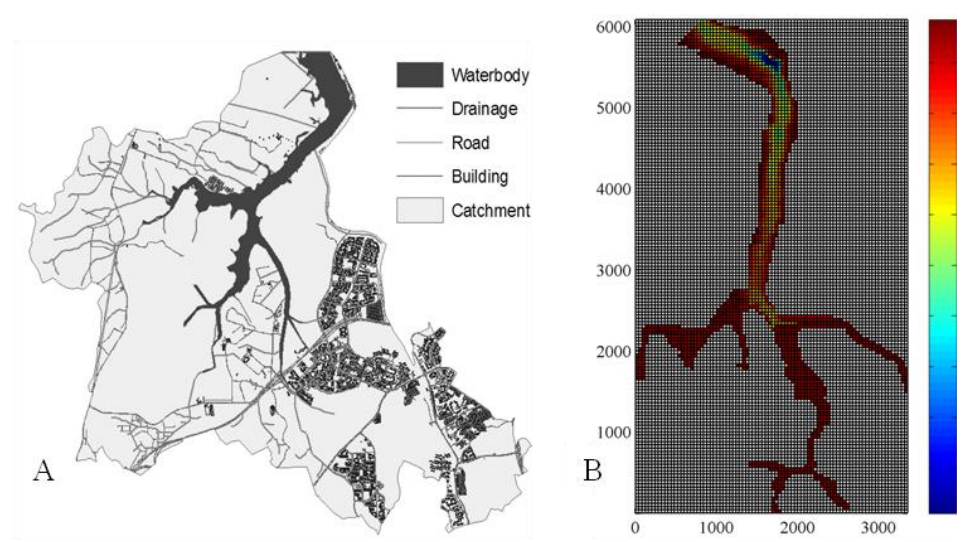

Figure 1. (A). Kranji Catchment and Reservoir and (B). Bathymetry of Kranji Reservoir used in ELCOM.

We apply an integrated three-dimensional hydrodynamics-ecological model to Kranji Reservoir, the Estuary Lake and Coastal Ocean ModelComputational Aquatic Ecosystem Dynamics Model (ELCOM-CAEDYM) developed by the Centre for Water Research, University of Western Australia [8, 9]. ELCOM-CAEDYM has been applied and evaluated widely in many different aquatic ecosystems around the world, including lakes, reservoirs, estuaries and oceans. ELCOM solves the hydrostatic, Boussinesq, unsteady Reynolds-averaged Navier-Stokes (RANS) and scalar transport equations [8]. CAEDYM provides a dynamic coupling with ELCOM, particularly calculating ecological processes including oxygen dynamics, nutrient cycling, and phytoplankton dynamics [9]. For the ELCOMCAEDYM model of Kranji Reservoir (Kranji model), we have assumed boundary condition of turbulent benthic boundary layer and used initial conditions from measured vertical water temperature and water quality profiles in the reservoir. The discretization of Kranji model consists of horizontal orthogonal grids with $40 \times$ $40 \mathrm{~m}$ wide cells as shown in Figure 1B. The grid size of $40 \mathrm{~m}$ is chosen taking into account the bathymetry map resolution and the simulation speed of the model. For the vertical direction, we have used a total of 21 layers for the maximum depth of 22.5 meters allowing for water level fluctuations. The near surface vertical resolution is 0.5 meter and decreasing gradually towards the bottom of water column to improve computational accuracy in the surface layers.

In this study, we have run the ELCOM-CAEDYM simulations for 2005 under a total of five management scenarios, including tests for hydraulic flushing, phosphorus load reduction, artificial destratification, sediment manipulation and algaecide addition. The first two belong to watershed management strategies while the others are in-lake treatment techniques. The details of the settings and results of each management scenario are presented and evaluated in the next section.

\section{Results}

\subsection{ELCOM-CAEDYM model for Kranji Reservoir}

Calibration of the Kranji model was carried out by using a combination of biogeochemical parameters obtained from both literature review of other tropical lakes and field measurements and laboratory analysis of water and sediment samples collected from Kranji Reservoir. The model was calibrated by tweaking of important biogeochemical parameters to fit observed data. The Kranji model was calibrated and validated against a two-year record (2005 and 2006) of water temperature and water quality variables [10].

The simulated results are compared with field measurements for the water surface of Kranji Reservoir in 2005 (see Figure 2). The calibrated model was found to be capable of predicting total chlorophyll-a (TCHLA), total phosphorus (TP) concentrations, total organic carbon (TOC) and total nitrogen (TN) concentrations 
fairly well. As TCHLA and TP concentrations are the most critical water quality variables for eutrophic lakes, the model can be used as an effective prediction tool to evaluate the management scenarios for controlling eutrophication in Kranji Reservoir. However, due to the scope of this study, the present model has not quantified the uncertainties from model parameters and input data. We will investigate the sensitivity of model parameters and the uncertainties of the model results in further studies.
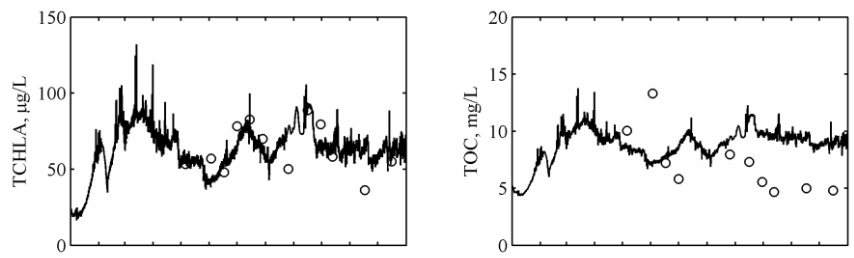

- Simulated $\bigcirc$ Measured
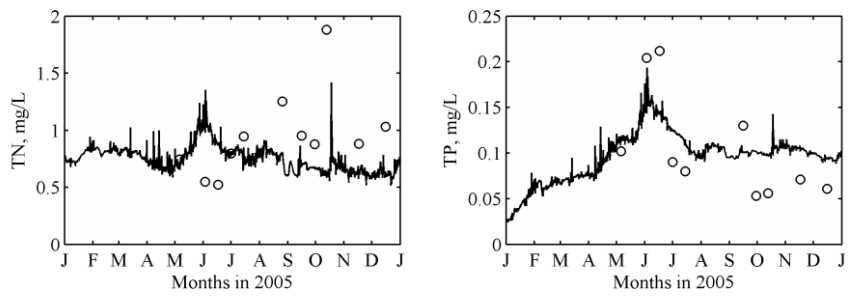

Figure 2. Comparison between measured and simulated water quality variables including total chlorophyll-a (TCHLA) concentration, total organic carbon (TOC) concentration, total nitrogen (TN) concentration and total phosphorus (TP) concentration at the water surface of Kranji Reservoir in 2005.

\subsection{Water Quality in Kranji Reservoir}

Three water quality variables measured 1-2 times per month over a 9 month period in 2005 and the TN:TP ratio computed based on these measurements are plotted in Figure 3. The TCHLA concentration was found to exceed the eutrophic level of $10 \mu \mathrm{g} / \mathrm{L}$ [11] for the months considered, with an annual mean concentration of $77 \mu \mathrm{g} / \mathrm{L}$. Algal blooms occurred from June to September where the mean TCHLA concentration reached $116 \mu \mathrm{g} / \mathrm{L}$ during this period. The total nitrogen (TN) and total phosphorus (TP) concentrations in the reservoir both increased in late July and gradually decreased thereafter, indicating increased nutrients input from inflows during the former period. The TN:TP ratio was found to be higher than the Redfield Ratio [12] of 7.2 (by weight) for most of the time throughout the year, thus the phytoplankton in Kranji Reservoir is considered to be phosphorus limiting. During the algal bloom period from June to September, the TN:TP ratio stays relatively low, indicating that the relative abundance of phosphorus combining with warmer weather during Jun to Sep tends to foster the algal blooms. In contrast, the TN:TP ratio increases significantly to well above 10 from October to December, coinciding with the notable decrease of TCHLA concentration. It suggests that the limited phosphorus combining with colder weather during Oct to Dec tends to suppress the algal blooms.
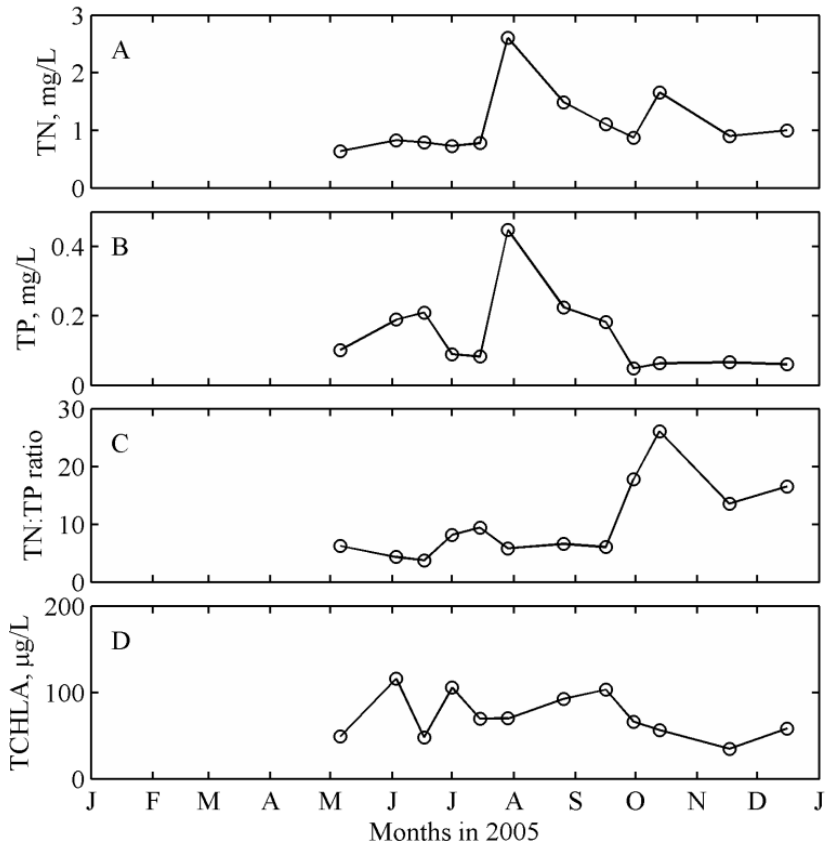

Figure 3. (A). Total nitrogen (TN) concentration, (B). Total phosphorus (TP) concentration, (C). TN: TP ratio and (D). Total chlorophyll-a (TCHLA) concentration measured at the surface of Kranji Reservoir in 2005.

\subsection{Management Scenarios Evaluation}

To control the eutrophication in Kranji Reservoir therefore, several management scenarios were evaluated. Of the watershed management strategies, hydraulic flushing is believed to be an effective technique in diluting the high-nutrient lake water and flushing out poorer quality water, thus reducing the phytoplankton population [13]. In the Kranji model, the inflow volumes from the tributaries were doubled. In reality, doubling of inflows could result from a diversion of inflows from nearby drainages. The model results show that a doubling of inflows can result in a reduction 
of $23.7 \%$ in the mean TCHLA concentration for 2005 (see Figure 4A). Though the reduction is significant, this method is not always feasible due to the high costs involved and availability of alternate sources of inflows.
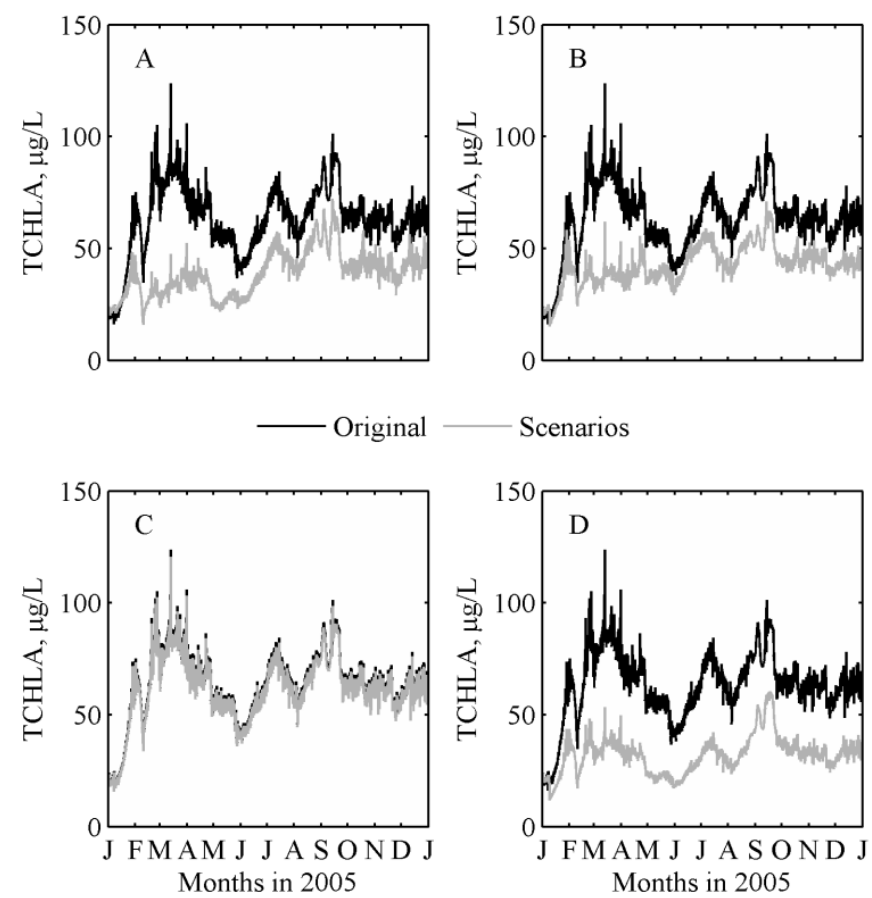

Figure 4. Simulations of TCHLA concentration under various management scenarios: (A) Hydraulic flushing, (B)

Phosphorus reduction, (C) Sediment manipulation, (D) Chemical treatment.

Reduction or removal of nutrients loadings from the inflows is one of the most commonly used lake restoration techniques. It can be achieved by best management practices such as wetland filtration [14, 15] or direct control and treatment of the point source discharges [16]. Since it is observed that algae in Kranji Reservoir is phosphorus-limited, we decreased the phosphorus loadings in inflows by $50 \%$. Such a reduction can be achieved through engineered systems or legislating against the use of phosphorus containing detergents. Our model results (Figure 4B) show that a $50 \%$ reduction in phosphorus loading can result in a $21.05 \%$ decrease in the annual mean TCHLA concentration. Inflow nutrient reduction is found to be an effective technique to control eutrophication. However, integrated water resources management in the watershed is required and techniques of filtration or treatment of the inflows need to be developed and implemented.
Aeration systems in lakes have been widely used to control eutrophication [17, 18]. Artificial destratification achieved by bubble-plume systems can add oxygen to the water column and improve mixing. In the Kranji model, simulations without bubblers and with bubbler operating at a rate of $0.20 \mathrm{~m}^{3} / \mathrm{s}$ were carried out and compared. Figure 5 shows plots of the simulated vertical profiles of mean TCHLA concentration at the location of bubbler with and without bubbler operation. Slight reduction of TCHLA concentration was noticed, affecting only the top 2 meters of water column with no discernible differences in the deeper parts of the water column. As a whole, bubbler operation resulted in only a $0.01 \%$ decrease in TCHLA concentration. Thus artificial destratification has limited use in Kranji Reservoir, probably because it is a shallow and polymictic system. The reservoir undergoes diurnal cycles of stratification and destratification induced by daytime heating and nighttime cooling. And unlike most temperate deeper lakes, there is no existence of seasonal thermocline in the reservoir. Thus the effects of the increased destratification contributed by the aerator on the reservoir water column are limited in comparison to diurnal destratification due to convective cooling.

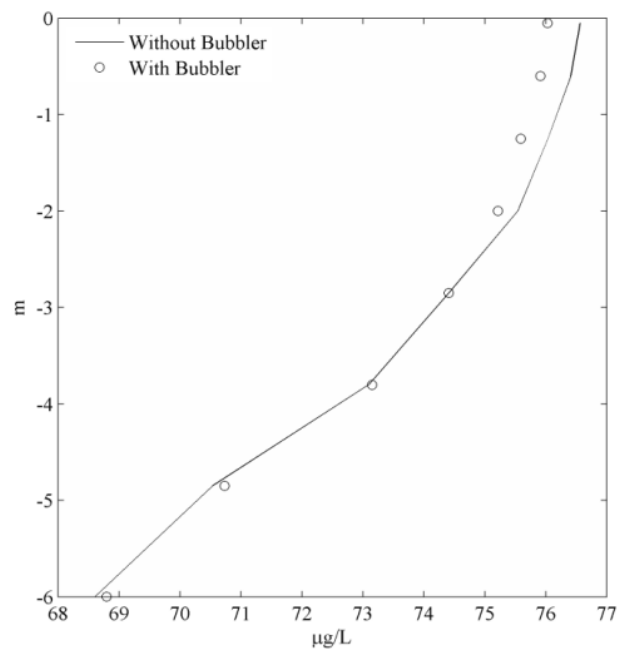

Figure 5. Simulated vertical profiles of mean TCHLA concentration at the location of bubbler in Kranji Reservoir under the conditions without bubbler and with bubbler operating.

Sediment manipulation in lakes is useful when internal nutrients sources from sediments account for a significant portion of the total nutrients for lake algal growth [19]. Typical techniques of sediment 
manipulation include sediment dredging and active barriers to reduce phosphorus release from lake sediments [20]. In the Kranji model, the effects of sediment manipulation have been tested by setting the initial nutrients concentration in the sediments to be zero, simulating the management scenario after a complete dredging of lake sediments. The results (Figure 4C) show that despite an extreme reduction in phosphorus release, only slight improvements in the lake water quality, a mere $2.6 \%$ reduction in TCHLA concentration, was obtained. Sediment manipulation is expensive and cannot solve the problem of water quality deterioration completely if there exist continuous excessive nutrients loadings from inflows.

Chemical treatments with the addition of algaecides such as copper sulphate, are considered to be an economical and effective technique to control cyanobacteria blooms [21]. In the Kranji model, the mortality rate of cyanobacteria was arbitrarily set to two times the calibrated value to simulate the effects of algaecide addition. The dosing of algaecide resulted in an average $36.17 \%$ decrease of TCHLA concentration (see Figure 4D). This represents the largest reduction in TCHLA among all the five management scenarios considered. Although the effect of controlling phytoplankton population is the most significant, there are potential drawbacks of this technique. The effects are temporal and the undesired taste, odour and toxicity associated with the use of algaecides which may cause adverse changes to other lake processes and ecosystem stability [22] are main concerns.

\section{Conclusion}

The effects of the five management scenarios, in terms of reductions in the TCHLA concentration and their respective advantages and drawbacks are summarized in Table 1 . It was found that hydraulic flushing, inflow nutrients reduction and algaecide addition had significant effects on the reduction of TCHLA concentration while artificial destratification and sediment manipulation had limited effects. Though algaecide addition is economical and effective, there are serious concerns in adopting this technique [22]. Compared to the latter three in-lake treatments, watershed management strategies were found to be the most effective with fewer drawbacks since inflows from the watershed can exert significant effects on the water quality of the lake. Of the management scenarios considered, phosphorus reduction was considered to be the best strategy. Integrated water resources management on the watershed level is critical towards preventing eutrophication.

Table 1. Effects of management scenarios on mean TCHLA concentration in Kranji Reservoir and the advantages and disadvantages of each management scenario

\begin{tabular}{|l|l|l|l|}
\hline \multicolumn{1}{|c|}{ Scenario } & $\begin{array}{c}\text { TCHLA } \\
\text { reduction }\end{array}$ & \multicolumn{1}{c|}{ Advantages } & \multicolumn{1}{c|}{ Disadvantages } \\
\hline $\begin{array}{l}\text { Hydraulic } \\
\text { flushing }\end{array}$ & $-23.68 \%$ & Significant reduction in TCHLA & $\begin{array}{l}\text { Expensive; not always feasible, need } \\
\text { integrated water resources } \\
\text { management }\end{array}$ \\
\hline $\begin{array}{l}\text { Inflow } \\
\text { nutrients } \\
\text { reduction }\end{array}$ & $-21.05 \%$ & Significant reduction in TCHLA & $\begin{array}{l}\text { Need integrated water resources } \\
\text { management and treatment of inflows }\end{array}$ \\
\hline $\begin{array}{l}\text { Artificial } \\
\text { destratification }\end{array}$ & $-0.01 \%$ & $\begin{array}{l}\text { Slight improvements at the } \\
\text { location of bubblers }\end{array}$ & $\begin{array}{l}\text { Negligible effects for the whole } \\
\text { reservoir }\end{array}$ \\
\hline $\begin{array}{l}\text { Sediment } \\
\text { manipulation }\end{array}$ & $-2.60 \%$ & Slight improvements in lake & $\begin{array}{l}\text { Expensive; the reduction of THCLA is } \\
\text { much lower than some other } \\
\text { techniques }\end{array}$ \\
\hline $\begin{array}{l}\text { Algaecide } \\
\text { addition }\end{array}$ & $-36.17 \%$ & $\begin{array}{l}\text { Significant reduction in } \\
\text { TCHLA; economical and } \\
\text { effective in controlling algal } \\
\text { blooms in lake }\end{array}$ & $\begin{array}{l}\text { Effects are temporal; taste, odour and } \\
\text { toxins may still remain in water; may } \\
\text { cause changes to other lake processes }\end{array}$ \\
\hline
\end{tabular}




\section{Acknowledgements}

This work is supported by the Singapore National Research Foundation under its Environment \& Water Technologies Strategic Research Programme and administered by the Environment \& Water Industry Programme Office (EWI), under project 1002-IRIS-09.

\section{References}

[1] T. Schueler and J. Simpson, "Why urban lakes are different," Watershed Protection Techniques, vol. 3, 2001, pp. 747-750.

[2] L. Naselli-Flores, "Urban Lakes: Ecosystems at Risk, Worthy of the Best Care," in Taal2007: The 12th World Lake Conference, 2008, pp. 13331337.

[3] S. Birch and J. McCaskie, "Shallow urban lakes: a challenge for lake management," Hydrobiologia, vol. 395-396, 1999, pp. 365-377.

[4] C. Walker, J. L. Lampard, A. Roiko, N. Tindale, A. Wiegand, and P. Duncan, "Community well-being as a critical component of urban lake ecosystem health," Urban Ecosystems, vol. 16, 2013, pp. 313326.

[5] V. H. Smith, "Cultural eutrophication of inland, estuarine, and coastal waters," in Successes, limitations, and frontiers in ecosystem science, ed New York: Springer, 1998, pp. 7-49.

[6] J. Lv, H. Wu, and M. Chen, "Effects of nitrogen and phosphorus on phytoplankton composition and biomass in 15 subtropical, urban shallow lakes in Wuhan, China," Limnologica, vol. 41, 2011, pp. 4856.

[7] Y. Zeng, "A risk assessment on the alga bloom in city-a case of the "six seas" urban lakes in Beijing," Procedia Environmental Sciences, vol. 2, 2010, pp. 1501-1509.

[8] B. R. Hodges, J. Imberger, A. Saggio, and K. B. Winters, "Modeling basin-scale internal waves in a stratified lake," Limnology and Oceanography, vol. 45, pp. 1603-1620, 2000.

[9] J. R. Romero, J. P. Antenucci, and J. Imberger, "One- and three-dimensional biogeochemical simulations of two differing reservoirs," Ecological Modelling, vol. 174, 2004, pp. 143-160.

[10] E. Y.-M. Lo, E. B. Shuy, K. Y. H. Gin, L. H. C. Chua, S. B. K. Tan, J. Imberger, J. Antenucci, M. Hipsey, and T. Brown "Water quality monitoring, modeling and management for Kranji catchment/reservoir
system-Phases 1 and 2 Rep., Public Utilities Board, Singapore.," 2008.

[11] H. Klapper, Control of eutrophication in inland waters: Ellis Horwood Limited, 1991.

[12] A. C. Redfield, "The biological control of chemical factors in the environment," American scientist, vol. 46, 1958, pp. 205-221.

[13] D. L. Roelke and R. H. Pierce, "Effects of inflow on harmful algal blooms: some considerations," Journal of Plankton Research, vol. 33, 2011, pp. 205-209.

[14] F. Cui, Q. Zhou, Y. Wang, and Y. Q. Zhao, "Application of constructed wetland for urban lake water purification: trial of Xing-qing Lake in Xi'an city, China," Journal of Environmental Science and Health Part A, vol. 46, 2011, pp. 795799.

[15] E. F. Lowe, L. E. Battoe, D. L. Stites, and M. F. Coveney, "Particulate phosphorus removal via wetland filtration: an examination of potential for hypertrophic lake restoration," Environmental management, vol. 16, 1992, pp. 67-74.

[16] S. W. Effler, S. M. O'Donnell, A. R. Prestigiacomo, D. A. Matthews, and M. T. Auer, "Retrospective Analyses of Inputs of Municipal Wastewater Effluent and Coupled Impacts on an Urban Lake," Water Environment Research, vol. 85, 2013, pp. 13-26.

[17] J. Grochowska, R. Brzozowska, and M. Łopata, "Durability of changes in phosphorus compounds in water of an urban lake after application of two reclamation methods," Water Science \& Technology, vol. 68, 2013, pp. 234-239.

[18] D. Hanson and D. Austin, "Multiyear destratification study of an urban, temperate climate, eutrophic lake," Lake and Reservoir Management, vol. 28, 2012, pp. 107-119.

[19] W. F. James, J. W. Barko, H. L. Eakin, and P. W. Sorge, "Phosphorus budget and management strategies for an urban Wisconsin lake," Lake and Reservoir Management, vol. 18, 2002, pp. 149163.

[20] B. Hart, S. Roberts, R. James, J. Taylor, D. Donnert, and R. Furrer, "Use of active barriers to reduce eutrophication problems in urban lakes," Water Science \& Technology, vol. 47, pp. 157-163, 2003.

[21] H. Qian, S. Yu, Z. Sun, X. Xie, W. Liu, and Z. Fu, "Effects of copper sulfate, hydrogen peroxide and 
N-phenyl-2-naphthylamine on oxidative stress and the expression of genes involved photosynthesis and microcystin disposition in Microcystis aeruginosa," Aquatic Toxicology, vol. 99, 2010, pp. 405-412.

[22] L. Song, T. L. Marsh, T. C. Voice, and D. T. Long, "Loss of seasonal variability in a lake resulting from copper sulfate algaecide treatment," Physics and Chemistry of the Earth, vol. 36, 2011, pp. 430435. 